\title{
The Core Components and Types of CRM
}

\author{
Hussein A. Al-Homery ${ }^{1}$, Hasbullah Asharai ${ }^{2}$, Azizah Ahmad ${ }^{3}$ \\ ${ }^{1}$ School of Technology Management and logistic. College of Business, Universiti Utara \\ Malaysia, Malaysia. \\ ${ }^{2}$ Associate Professor, Department of Management and Humanities, Faculty of Science \& \\ Information Technology, Universiti Teknologi Petronas, Malaysia. \\ ${ }^{3}$ Institute for Advanced and Smart Digital Opportunities, School of Computing, Universiti \\ Utara Malaysia, Malaysia. \\ Email: homeryh65@yahoo.com
}

\begin{abstract}
This paper highlights the influence of knowledge on the customer relationship as the fourth core component of the CRM components which are technology, people and business processes. The fourth component emerges as a result of the advancement in technology, telecommunications, and the excess in customer information in the era of information. Moreover, this paper highlights the new fifth type of CRM namely "Showroom CRM". Besides, the other CRM types are strategic CRM, Operational CRM, Analytical CRM and Collaborative CRM. The fifth type is a comprehensive business framework which includes the structure of the other types of CRM. Moreover, the researcher surveyed the web and listed a 250 CRM system packages and programs available in the software market. The summary and classification of the 250 CRM system is given in table (1) of appendix A of the study.
\end{abstract}

Keywords: CRM components, Knowledge Management, CRM Types, Showroom CRM, Customer Knowledge Management

\section{Introduction}

To understand any system or business strategy or process, we should start with what this system designed for by look into the system definition. Thus, the definition of any system gives you the features and indications of the system elements design and purpose. The second question is what the components of that system are and how these components work together for the success of the system. Then comes the implementation or the adoption process.

Customer relationship management "CRM" literature reveals a variety of understanding for CRM definitions and its components. However, in this article main three components of CRM and their relevant items are discussed which are business process, people and technology. In addition, we are going to discuss our vision for the fourth core 
component which is customer information or customer knowledge. In the last section, we are going to review the CRM types in addition to our vision for the fifth type the "Showroom CRM" which is a comprehensive type of CRM.

\section{CRM Components}

CRM main components are businesses processes, technology and people (Almotairi, 2008). CRM is not a technology rather it is a business process designed strategically which includes the management of customer relationship (Gray \& Byun, 2001). Furthermore, Payne (2004), Shang and Lin (2005), and Payne and Frow (2005) posited that CRM refers to the strategic approach which assimilates technology with the business process to function together for building a long-term profitable relationship with the customers (Shang \& Fen, 2006). As a strategic view, CRM refers to the business functions operated through corresponding processes which is realized through corresponding information system. The three main components are strategy, technology and human beings (Reicher \& Szeghegyi, 2015). In their strategic framework, Payne and Frow (2005) divided the CRM assessment process into two components namely; shareholder results and performance monitoring. Furthermore, Zablah, et. al. (2004) maintained that the CRM conceptualization is a combination of five perspectives which are strategy, philosophy, process, technology tool, and organization capability.

It is revealed in the research of Al-Khouri (2011) that there exists a positive relationship between CRM components and profitability of the firm. Therefore, the proper integration of CRM components ensures successful adoption results (Baksi, 2013; Bull, 2003; Chen \& Popovich, 2003; Mendoza et al., 2007; Rahimi, 2014; Rahimi \& Gunlu, 2016; Rahimi, et al., 2015; Zablah, et al., 2004). In the same context, Almotairi (2009) stated that the success of CRM is basically built on the management, integration and control of the component of CRM components. The CRM components thoroughly depend on the organizational business activities and the environment. Accordingly, it varies from one organization to another. Many researchers have categorized the CRM components into three main components namely; people, technology, business culture and relationship, and the process (Ali \& Alshawi, 2003; Almotairi, 2009).

The strategy, the process and the information system are the three interrelated conceptual components of CRM. Recent trends in CRM add knowledge as the fourth core component of CRM (Myron, 2015). 
Pakistan Journal of Humanities and Social Sciences, 7(1), 2019

\section{A. Technology}

Technology has been the basic outlet to achieve the CRM system objectives and an important component for collecting, classifying, and saving customers' data (Chang et al., 2010; Jayachandran et al., 2005; Rapp et al., 2010). Undoubtedly, the integration of technology allows a wider view for organizations' customers' data (Thompson et al., 2006). It is through integration that organizations realize and be aware of the customers' behaviors, develop predictive models, and track effective communications in response to the customers in the required time (Chen \& Popovich, 2003). On a large scale, recent technological changes are enabling the firms to improve their capabilities of handling customer needs while retaining existing and attracting new customers (Chang et al., 2010).

Thus, the integration concept, for organization, means to have an internet software, help desk, call center, software customization, data warehouse and process automation as a complete integrated process for business and system (Almotairi, 2009; Mendoza et al., 2007). Accordingly, higher retention of customers through improved customer satisfaction and an enhanced gainful long-term customer relationship are among the major desired and targeted results for the firms from the CRM-based technology (Yim et al., 2005).

Technology implies three categories of information regarding CRM related systems namely; Transaction systems, Enterprise Resource Planning (ERP) and Knowledge Management (KM) systems. The Meta Group categorized CRM systems into three classifications namely; operational CRM which comprises of solutions for sale and service automation and marketing, analytical CRM which supports CRM analysis processes, and Collaborative or Communicational or Interactive CRM which manages and synchronizes the points of customer interactions and communication channels.

The CRM systems are processing well-structured information (Buttle, 2009). The CRM systems classification will be discussed in detail in CRM types section, where the researcher proposes Showroom CRM as the CRM fifth type.

The CRM systems had started within a limited scope to serve specific customer tasks, manage customers and measure their satisfaction. The CRM system packages can be classified into many software categories. The most prominent categories are Call center, Leads management, Process management, Sales process or Sales automation process, Service management, Helpdesk systems, Knowledge and opportunity management, Customer support and service, Sales workflow, Field service management, Predictive analytics and Workflow process. The researcher has surveyed the web and listed around 250 CRM software packages 
and programs given in Appendix-A. The packages/ programs are classified into nine categories and summarized in the CRM software related packages.

By looking at the table of CRM software categories in Appendix-A, we can figure out that the variety of CRM software packages with different names reflect the confusion of the software providers about what CRM software is expected to deliver. As, some considered it as a call center, a help desk, a contact management, or an email tool while, others consider it as sales force automation (for sales process / marketing process / services process) and others considered it as an ERP and so on. Practically, the variety of CRM concepts lead to variations in the scope of designing the CRM software packages. The variety in scope design leads to weak results from CRM implementation to get as the strategic view of the CRM as a life style process or as a comprehensive integrated business process as per the organization workflow process.

In fact, the Knowledge Management systems or effective transformation of customers' data into customer knowledge is required in the process of CRM delivery for satisfying the needs of the customers. Knowledge Management (KM) systems facilitate the flow of knowledge around customer issues. The integration of knowledge management and CRM helps companies to have a better understanding of the customer needs, demands and behavior (Nejatian et al., 2011; Plessis \& Boon, 2004; Rahimi, 2017).

Customer Knowledge has been classified into two types; Attitudinal or Qualitative and Behavioral or Quantitative knowledge. Others have categorized the CKM into four types: content; competence, collaboration and composition (Sanayei \& Sadidi, 2011). The process of CKM can be further divided into three different micro-processes which are data collection process, intelligence generation process and intelligence dissemination process (Rababah, et. al, 2011; Zablah, et. al., 2004). The process of KM depends upon database technology for customers' data manipulation and distribution of actionable intelligence. The ability of such intelligence affects firms' interaction management efforts (Zablah, et. al., 2004).

The process of interaction management depends upon CRM technology in developing marketing campaigns and multichannel communications among purchaser's customers for understanding customers' behaviors. The key dimensions of the interaction management quality are consistency, relevance and appropriateness (Zablah, et. al., 2004). Many scholars considered the interaction management as the CRM micro process approach (Öztaysi, Sezgin et al. 2011). This micro process approach is totally concerned with the customer interaction 
Pakistan Journal of Humanities and Social Sciences, 7(1), 2019

management to sustain a long-term profitable relationship, while macro-level process concentrates on the CRM as a company-wide process (Gholami \& Sabbir Rahman, 2012).

In conclusion, knowledge management (macro-level process) and interaction management (micro-level processes) are the main categories of the CRM process. On the other hand, the Enterprise Resource Planning (ERP) system and Transaction system hold great relevance to the CRM since structured information is processed and stored on customers' database master in addition to the business transactions. While CRM analysis processes need such data for obtaining a 360 degree perspective of customers since the processes of CRM delivery and support require access to all the data of company's customers to better and fully tackle their needs.

\section{B. People}

It is highly agreed that staff or employees in an organization are among the vital success determinants who manage the customer relationship and the organizational readiness (Chakravorti, 2006; Rahimi, 2017). The management and the staff in an organizations hold crucial importance in a successful and effective implementation of CRM (Almotairi, 2009). CRM technology relates to automation of information processing for increasing employee efficiency and effectiveness and manage customer relationship of the organization (Ahearne, Hughes, \& Schillewaert, 2007; Crittenden, Peterson, \& Albaum, 2010). Moreover, Employee Relationship Management (ERM) is a contemporary issue in the management of human resource based on CRM.

\section{CRM Business Process}

The CRM Business Strategy derives philosophical foundation of the relationship marketing (Chen \& Popovich, 2003). The success of CRM entails a sharp shift of all the business processes to customer-oriented processes; the analysis and assessment of all the business processes must be customer centric (Mendoza et al., 2007; Rahimi \& Gunlu, 2016). The CRM immensely requires efficient and integrated business systems with organizationwide impact in developing a customer single view of sharing across the organization. The impact of such organizational processes should be prioritized when integrated and automated as business processes bearing in mind the main effective business processes namely; marketing process, sales process and services process (Alkhouri, 2012; Mendoza et al., 2007).

The CRM involves pertinent business processes identified as a result of comprehensive assessment and analysis. The CRM processes are categorized into three levels namely; company level, functional level and customer level (Moutot \& Bascoul, 2008; Ragins 
\& Greco, 2003). The customer-facing level of CRM have three stages of CRM process namely; relationship initiation, relationship maintenance and relationship termination. Thus, it emphasizes that the customers should be viewed in a single viewpoint across all the channels of contact and customer intelligence distribution (Rababah et. al., 2011; Ragins \& Greco, 2003).

The classification of Customer-Oriented CRM Processes is three-fold namely CRM; delivery, support and analysis process (Geib, Reichold, Kolbe, \& Brenner, 2005; Rababah et al., 2011). There are five classifications of the cross-functional CRM processes which are the process of developing strategy, the process of creating value, the process of multichannel integration, the process of information management and the process of performance evaluation.

In conclusion, the complementary, detailed and comprehensive perspective is crossfunctional CRM process perspective. Moreover, this perspective nests all other perspectives. For instance, the process of multichannel integration includes the process of customer level. Meanwhile, the process of CRM analysis, the CRM delivery and support, and the process of customer-oriented CRM can respectively be found rooted in the process of information management, the process of value creation and the process of multichannel integration.

Likewise, the iterative process of CRM relationship is explained through the perspective of customer level process which starts with introducing, maintaining and enhancing the relationship to the customer. It also involves the termination of the relationship with the customer once it is no more profitable to the company. On the other hand, the perspective of macro-level CRM process has revealed too high-level CRM processes at company level (Rababah et al., 2011). The researcher considers the macro level process as the detailed and the pattern of the organizational processes towards organizational goal achievements.

The business processes are identically the veins of the organizational operations. So, CRM scholars classified CRM into four types which will be discussed later in this article. The operational type is the main of those types. The Operational CRM has been classified into three main categories namely; Enterprise Marketing Automation (EMA) or Marketing Automation (MA), Customer Service and Support (CSS) or Service automation (SA) and Sales Force Automation (SFA) (Albadvi, 2003; Buttle, 2009). It is at the discretion of the organization to select any as a separate solution or integrate them together, see Table (1), Appendix-A, (Pedron \& Saccol, 2009; Tamosiuniene \& Jasilioniene, 2007). 
Pakistan Journal of Humanities and Social Sciences, 7(1), 2019

\section{Sales Force Automation}

Sales force automation (SFA) refers to a technology application for supporting sales consultants and management to achieve their job relevant objectives (Buttle, 2009). The automation in the CRM systems is meant for the business processes that are integrated horizontally for the service and marketing front office touch points through interrelated channels of delivery. The integrated packages can be authentically dedicated to an inclusive CRM suite or sales-force application that function over the sales, service and marketing frontoffices. The same is supported by Payne and Frow (2005).

SFA helps motivate sale teams to achieve sale targets through offering solutions to the problems of sales management that are time-efficient and enhance the productivity and efficiency by eliminating redundancies, thus augment CRM performance (Pedron \& Saccol, 2009).

SFA solutions providers are classified into three categories. First category is SFA specialists whom focus is on specific functions in SFA. Second category is SFA as part of CRM Suite where the CRM suite includes SFA module and the third category is SFA as part of an enterprise suite which provides a complete IT solutions range like "Supply Chain Management" (SCM), "Enterprise Resource Planning" (ERP), "Customer Relationship Management" (CRM) as given in Table (1) of Appendix-A.

SFA should be integrated with different communication technology channels such as web, e-mail, telephone or call center, where SFA systems should be able to operate outside office and across the web (Buttle, 2009; Speier \& Venkatash, 2002) as given in Appendix-A.

SFA software is offering a range of functionalities varying from one to another, but in common, most of these functions in any software packages handle sales force automation process. As a common concept in sales management, sales start from lead management. In other words, it ask the question of how to capture the leads (the prospects). Then, following up these leads through a follow-up system (workflow engineering), managing customer contacts through (contact management) customer events, campaigning events (event management), the stored document (document management), customer quotation (quotation management) and customer order (order management). Then, after delivering the product to the customer, the process of follow up starts after sales process and forecasting for sales processes. More than one study has investigated the effects of SFA on sales performance such as improvements of sales consultants' selling skills, knowledge, performance, marketing knowledge, technical knowledge, targeting skills and so on (Ahearne \& Schillewaert, 2001; 
Engle \& Barnes, 2000; Erffmeyer \& Johnson, 2001), But, on the other hand, there are still a number of conditions to be met for the SFA in order to have a tangible impact on sales performance. These include ease of use, accurate expectation, task list of the sales, involvement of users and user groups, and support).

\section{Marketing Automation}

Marketing automation refers to a technology application which helps marketing personnel and management in achieving their job-relevant objectives (Buttle, 2009). According to Cho, et al. (2002), marketing automation is providing information regarding products, campaigns, customer profiles and so on. It benefits the organization through creating marketing productivity, improved marketing intelligence, improved responsiveness and a better customers' experience. It helps sales force to access marketing information fast and effectively targeting the right customers at the desired time (Tamosiuniene \& Jasilioniene, 2007).

The marketing automation software varies in its functions and most of the available functions include the management of; assets, documents, campaigns, direct mail and email campaign, loyalty, marketing performance, product lifecycle, marketing resource, market and customer segmentation, enterprise marketing, internet marketing, event-based marketing, keyword marketing, lead generation, marketing analytics and optimization, optimization of search engines, partner marketing, trigger marketing, telemarketing, workflow engineering, and web analytics.

\section{Service Automation}

Service automation (SA) is a technology application for supporting service management and personnel to achieve their objectives. Service Automation (SA) is mainly utilized in five major areas: call centers, contact centers, field service, help desks and web self-Service.

In service quality, there are two main perspectives; quality either be specification conformance or fitness for the purpose (Buttle, 2009; Crosby, 1979; Juran, 1964). The service quality has three components namely; technical, functional, and reputational (Buttle, 2009; Gronroos, 1984).

The value propositions of the organizations are integral components of strategic CRM. Value propositions of an organization refer to the implicit and explicit promises to company's customers by the organization for delivering specific value-creating benefits. 
Service automation offers numerous benefits to the companies like enhanced customer experience, increased service productivity and improved service efficiency (Buttle, 2009).

The service automation software varies in its functions and most of the available functions include but not limited to; the management of agents, activities, cases, contracts, email response, service level, spare parts, inbound and outbound communications and jobs, driving and mapping directions, case assignment, assembly lining up and directing routes, scheduling, scripting, invoicing, self-service of customers, service analytics, escalation, web collaboration, and workflow engineering (Buttle, 2009).

In the previous business process sections, the researcher actually has listed the three common functions of any organization in general namely; sales, marketing and service automation. The process handling and automation of customer relationships vividly play the greater part in achieving the organizational goals.

\section{Knowledge}

The new emerging component is knowledge. The advancement in technology and innovations intensify the knowledge base in contemporary knowledge-based economies. In today's business, the organizations are highly dependent upon knowledge for sustaining a competitive advantage in building relationships with customers. Customer knowledge is classified into three distinct groups; knowledge from customers, knowledge to customers and knowledge about customers. The knowledge for customers is developed in the organizations from knowledge about and from customers (Wu et. al., 2019). The high customer knowledge encourages the customer confidence which in turn, encourages the repurchasing intentions (Liza, 2019). Moreover, the knowledge management has a major effect on the corporate performance (Shu-Mei, 2016). Furthermore, it has an effective impact of leverage across supply chains (Nguyen \& Harrison, 2018). In addition, the sharing in communities and groups, relationships, conversations, ease and speed of use and other social media revolution capabilities exploit the customer knowledge for the organizations with novel prospects to establish significant and effective relationships (Sanaz et., al., (2017).

In reference to the above scholars statements and what we explained before in Section 2.1 about knowledge management and knowledge integration (Eslami \& Lakemond, 2016), the opinion of the researcher is that the fourth core component of CRM is Customer Knowledge. The CRM types are discussed in next section. 


\section{The CRM Types}

CRM can be described as a business strategy and an cohesive process which deals with the selection and management of customers for long-term value optimization for the organizations. The CRM is used by the organizations for identifying, attracting, satisfying and maintaining a good relationship with their partners and potential and existing customers. There are many researchers who classified CRM into two main categories, three groups of categories and four types. The researcher lists two main categories and four main types as a comprehensive approach. Moreover, the researcher has maintained that there are found types of CRM. The first category will be considered implicitly as one of the main four types of the second category (strategic CRM, operational CRM and collaborative CRM).

Others went to categorize the CRM into three distinct groups namely; interactive or collaborative, transactional or operational, and analytical. Buttle (2004), and Iriana and Buttle (2006) have classified the CRM types into strategic, operational and analytic CRM. Buttle (2009) has classified the CRM levels into four levels namely; strategic, analytic, collaborative and operational. The types of CRM can be broadly understood via monitoring two different ways.

\section{A. The Proactive versus Reactive CRM}

Reactive CRM means that the company responds to the customers' recommendations, suggestions, complaints and act accordingly. Customer service operations in general, and call centers in particular, focus mainly on 'reactive' relationship with the customers. The reactive method might satisfy the customers, but it will not surprise or delight them (csi.softwareadvice.com, 2013).

Divergent to this, the Proactive CRM comes true when an organization forecasts and responds to the needs of the customers anonymously and spontaneously. The proactive customer supporting operation does not wait for complaints to be registered but actively seeks to discover and manage customer dissatisfaction. Practically, the proactive customer care initiatives that are carefully designed are much more rewarding and effective.

\section{B. The Operational, Collaborative and Analytical CRM}

Lexically, Anton's (2002) total CRM system has two overwhelming components; analytical and operational CRM. Specifically, it is combining a fully integrated CRM system to the current one. Anton (2002) stated that combining the operational CRM within the analytical CRM together may help in enhancing chances of service provision to the customers, which in turn, increases the return on investment (ROI) (Nuri, 2014). 
Pakistan Journal of Humanities and Social Sciences, 7(1), 2019

Here, we are going to list the four basic types of the CRM starting with the CRM strategy which implicitly represents the first category mentioned in Section 3.1.

\section{The Strategic CRM}

Strategy is lexically defined by Grant (1998) as a comprehensive strategy to deploy resources to achieve their goals on the long-term stream. These resources are deliberately meant for developing and maintaining the potential relationships and efforts need to be assigned together on the basis of firms' profitability (Zablah et al., 2004).

Hence, it aims to construct a creative firm where strategies are developed for consistently innovating and delivering value to the customers in such a way that is better than other relevant competitors in addition to designing processes that create value for customers (Buttle, 2009), (which implicitly represents the first category).

Therefore, the core emphasis of strategic CRM is laid on creating the business culture that is customer-focused through which competitive advantage is gained. Unquestionably, this may come true via taking crucial decisions with which we can enhance better investment in the organizational resources (Iriana \& Buttle, 2006). Furthermore, Gartner (2001) has called for a new way of thinking and rethinking for business processes to be re-engineered in order for setting up a more customer centric culture. This view was supported by Kale (2004) who noted that embarking upon the identification of entire strategic process takes place between the firm and its customers is a critical aspect of CRM. The challenge of adopting this new approach comes from identifying the key generic processes relevant to CRM (Hansotia, 2002; Mendoza et al., 2007; Rahimi \& Gunlu, 2016).

\section{The Operational or Transactional CRM}

The operational CRM apparently deals with the customers' automation processes through applications that handle mobile and front-back offices including enterprise marketing automation, customer service and support, and automation of sales force as given in Appendix-A in Table (1). Correspondingly, the streamlining of workflow and automation at front office is dealt through operational CRM which includes data collection, transaction processing and workflow control at service, marketing and sales departments (Dyche, 2002; Lun, Jinlin, \& Yingying, 2008; Raisinghani, 2005; Zhang, Chen, \& Fu, 2006).

Historically, the operational CRM has remained a main part of the expenditures of enterprises since organizations continually adopt automation systems for sales force and develop process applications. Thus, the vendors of CRM basically focus at providing a more and more broader range of solutions (see Appendix-A, Table (1)). It is agreed that the purpose 
of operational CRM is the integration of technology, processes and people through the expectations and perspectives of the customers.

Furthermore, Buttle (2009) stated that both the customer-supporting and customerfacing business processes are automated and improved in operational CRM. The functions of services, selling and marketing are automated and integrated intrinsically through the application of CRM software. As a result, the operational CRM is considered as an efficient approach that is cost-effective in CRM as all the interactions, processes and procedures are consolidated using internal processes of the organization (Boulding, Staelin, Ehret \& Johnston, 2005; Chan, 2005; Frow \& Payne, 2009; Paas \& Kuijlen, 2001; Parvatiyar \& Sheth, 2001; Paulissen et al., 2005; Zablah et al., 2004). Moreover, Xu and Walton (2005) stated that the support services, call center applications and management of contact is done by approximately all the CRM systems as given in Appendix-A, Table(1).

Eventually, the organizations have gained benefits from the operational CRM as a drive for cost reduction, enhanced revenue, quick solutions to the problems and gaining a comprehensive perspective of the company's customers with mutual interactions. Therefore, Bose (2002) asserted that CRM refers to the integration of business processes and technologies for satisfying the customers' needs in all interactions.

\section{The Analytical CRM}

The analytical CRM refers to enhance the value of the organizations and customer's base using the data of the customers generated by operational tools for managing the business performance. Moreover, the focus of analytical CRM is to intelligently mine the customerrelated data for tactical or strategic purposes. Moreover, analytical CRM involves the collection, mining, integration, organization, processing, analysis, interpretation and use of data generated from the operational aspect of the businesses to enhance both customers and company value added (Buttle, 2009; Dyche, 2002; Gefen \& Ridings, 2002; Lun, Jinlin, \& Yingying, 2008; Zhang, Chen, \& Fu, 2006). Therefore, the integration of operational and analytical CRM solutions is an imperative contemplation for success and effectiveness of CRM system processes, Appendix-A, Table (1).

Analytical CRM has become an integral part of several CRM implementations. Thus, analytical CRM can lead companies to decide that selling approaches should be different among different groups of customers. Moreover, there is a need to tailor the style and content of the customer communications. This increases the possibility of acceptance of a particular offer by the customers. The viewpoint of customers regarding analytical CRM is that it 
should; timely deliver, offer customized solutions to individual problems of the customers, which further enhances customer satisfaction. The viewpoint of organization regarding analytical CRM is that it should offer prospect of an enhanced and powerful up-selling and cross-selling programs, which further retains existing customers and attracts new customers.

The analytical CRM is a stepwise procedure where we have a source of data containing customers' detailed historical data within operational integration. All the important and essential information related to customer relationship processes, marketing potentials and activities can be obtained from it (Limayem, 2006).

To sum up, an analytical CRM has the potential to decrease the customer dissatisfaction since it identifies customers who are no longer loyal to the organization. Besides, the classification of customers is also done in analytical CRM and it enhance sale volumes through customizing its approaches of selling. Overall, it improves the whole supply chain management since it controls cost and enhances revenues. It also has the potential to investigate the system weaknesses and subsequently turns those weaknesses into opportunities and strengths.

\section{The Collaborative or Interactive CRM}

Jill Dyche (2002) defines "Collaborative CRM as a specific functionality that enables a two-way communication between a company and its customers through a variety of channels to facilitate and improve the quality of customer interaction".

Collaborative CRM involves the use of collaborative services and infrastructure to make the interaction between customers and company multiple channels possible. This enables interaction between customers, the enterprise, and its employees. The focus is on maintaining relations with partners to facilitate coordination in the business of the organization for more profitable identification, attraction, retention and development of customers.

Collaborative CRM allows valuable information to be shared along the supply chain. Thus, some CRM technology vendors have developed partner relationship management (PRM) applications that enable companies to manage complex partners or channel ecosystems and reduce the costs of a partner or channel management. "PRM" allows companies to manage the distribution of funds, plan and control promotions and measure outcomes. Sometimes, the term collaborative CRM is used to describe the application of these same technologies to internal communications such as across sales, marketing and service functions (Buttle, 2009). 
Collaborative CRM integrates call centers, enabling multi-channel personal customer interaction. It is a solution that brings people, processes and data together so companies can better serve and retain their customers. The data and all sorts of information might be structured, unstructured, conversational, and/or transactional in nature. The same is agreed by Limayem (2006) who stated that collaborative CRM has the ability to integrate a view of the customers while the interaction is taking place at the transaction level.

\section{The Showroom CRM}

By reviewing the above types of CRM, there is still a need for a comprehensive CRM type or in some aspects, we could say the specialty of the business where this type can represent the operational CRM as the front office for the business customers' interactivities contacts. It will represent the back office as manipulation and analysis to insight customers' data for business intelligence and sharing such knowledge among business partners' patterns as well as customers towards the business assigned goals for profitability and organizational expansion. In addition, measuring the customer satisfaction to have a loyal customer for life. Thus, it can be stated that this new proposed type of showroom CRM is an all in one structured design.

The components of this type are salesforce automation, marketing automation and service automation. The sales process is connected to marketing, service, logistics and support department which means that the sales processes are affected by all interrelated departments of the organization as well as strategies, policies and procedures. This type will include all four previous CRM types together (strategy, operation, analysis and collaboration). The integration between systems and processes of departments of the organization is the main player in the proposed type as a success factor for achieving the organizational goals.

The Showroom CRM type has the ability to integrate a view of the customer while the interaction is taking place at the transaction level and upon the company performance level. The researcher considers the new proposed type showroom CRM can be a framework as a complete business solution starts from the multichannel interactive sales process till delivery of the product/service to the customers and follow up the customer as a lifetime transaction.

\section{Conclusion and Recommendations for Future Research}

The study highlighted more than one aspect in CRM literature;

First, it highlights the confusion of the CRM software design and there is no specific parameter or specification for what CRM package should be as we see that helpdesk, call 
center, email management or sales process software called as a CRM package. The classification and the summary are given in the Appendix-A of the study.

Second, it highlights the emerging fourth core component "Knowledge" or the Customer knowledge and its effect on the other three components (Technology, people, and Business process). In addition, the effect on the organizational performance, business innovations, and the business goal achievements is also discussed.

Third, it highlights new "Showroom CRM" as the fifth type of the CRM types. It is a comprehensive type as it includes the other four types in it is structured framework. The fifth type is proposed for business specialty.

The paper opens new research venues for practitioners and academicians for further investigation. 


\section{References}

Ahearne, M. and Schillewaert, N. (2001), "The acceptance of information technology in the sales force”, eBusiness Research Center, Working paper 10-2000. Penn State University.

Ahearne, M., Hughes, D. E., \& Schillewaert, N. (2007). "Why sales reps should welcome information technology: Measuring the impact of CRM-based IT on sales effectiveness". International Journal of Research in Marketing, 24(4), 336-349.

Albadvi, A. (2003), "Customer Relationship Management (CRM)", Presentations retrieved on $14^{\text {th }}$ June, 2014.

Ali, M. and Alshawi, S. (2003), "Cultural Universality versus Particularity within e-CRM Systems: A Special Case of Information Systems", Brunel University: http://bura.brunel.ac.uk/handle/2438/1889.

Al-Khouri, R., (2011). "Assessing the risk and performance of the GCC banking sector". International Research Journal of Finance and Economics, 65, 72-78.

AlKhouri, A. M. (2012), "Customer Relationship Management: Proposed Framework from a Government Perspective", Journal of Management and Strategy, 3(34), 19233965. http://doi.org/10.5430/jms.v3n4p34.

Almotairi, M., (2008), "CRM success factors taxonomy", European and Mediterranean conference on Information Systems, May (2008), 25-26.

Almotairi, M., (2009) "A Framework for successful CRM Implementation", European and Mediterranean conference on information systems, July, 2009, 13-14.

Anton, J. and Hoeck, M. (2002), "E-Business Customer Service", Santa Monica, CA: The Anton Press.

Baksi, A.K., (2013), "Exploring nomological link between automated service quality, customer satisfaction and behavioral intentions with CRM performance indexing approach: Empirical evidence from Indian banking industry". Management Science Letters, 3, 1-22.

Bose, R., (2002), "Customer relationship management: Key components for IT success", Industrial Management \& Data Systems, 102, 89-97.

Boulding, W., Staelin, R., Ehret, M., and Johnston, W. J. (2005), "A Customer Relationship Management Roadmap: What is Known, Potential Pitfalls, and Where to Go", Journal of Marketing, 155-166.

Bull, C., (2003), "Strategic issues in customer relationship management (CRM) implementation", Business Process Management Journal, Vol. 9 No. 5, pp. 592-602.

Buttle, F., (2004), "Customer relationship management: concepts and tools", Oxford, Elsevier Butterworth-Heinemann.

Buttle, F., (2009), "Customer relationship Management: Concepts and Technologies", Oxford, Elsevier.

Chakravorti, S., (2006), "Customer relationship management: a content analysis of issues and best Practices".

Chan, J.O., (2005), "Toward a Unified View of Customer Relationship Management", the Journal of American Academy of Business, Cambridge, March, 2005.

Chang, W., Park, E.J. and Chaiy, S. (2010), "How does CRM technology transform into organizational performance? A mediating role of marketing capability", Journal of Business Research, Vol. 63,pp. 849-855.

Chen, I.J., and Popovich, K., (2003), "Understanding customer relationship management (CRM) People, process and technology”, Business Process Management Journal, Vol. 9 No. 5, pp. 672-688. 
Pakistan Journal of Humanities and Social Sciences, 7(1), 2019

Cho, Y., Im, I., Hiltz, J. and Fjermestad, J., (2002), “An analysis of online customer complaints: implications for web complaint management", Proceedings of the 35th Hawaii International Conference on System Sciences. Los Alamitos, CA. IEEE Computer Society.

Crittenden, V. L., Peterson, R. A., \& Albaum, G., (2010). "Technology and business-toconsumer selling: Contemplating research and practice". Journal of Personal Selling and Sales Management, 30(2), 103-110.

Crosby, P.B., (1979), “Quality is free”, New York: McGraw-Hill.

Croteau, A., and Li, P. (2003), "Critical success factors of CRM technological initiatives", Canadian Journal of Administrative Sciences, 20(1), 21-34.

Dyche, J., (2002), "The CRM Handbook: A Business Guide to Customer Relationship Management", Addison-Wesley.

Engle, R.L. and Barnes, M.L., (2000), "Sales force automation usage, effectiveness, and cost benefit in Germany, England and the United States", Journal of Business and Industrial Marketing, Vol. 15 (4), pp.216 - 242.

Erffmeyer, R.C. and Johnson, D.A. (2001), "an exploratory study of sales force automation practices: expectations and realities", Journal of Personal Selling and Sales Management, Vol. 21(2), spring, pp. 167-175; Ingram, T.N., LaForge, R.W. and Leigh, T.W. (2002) Selling in the new millennium: a joint agenda. Industrial Marketing Management, Vol. 31(7), pp. 559-567.

Frow, P.E. and Payne, A.F., (2009), "Customer relationship management: a strategic perspective", Journal of Business Market Management, Vol. 3 No. 1, pp. 7-27.

Gartner (2001), "CRM at work: Eight characteristics of CRM winners", Available at: www.gartner.com

Gefen, D., \& Ridings, C. M., (2002). "Implementation Team Responsiveness and User Evaluation of Customer Relationship Management: A Quasi-Experimental Design Study of Social Exchange Theory". Journal of Management Information Systems, 19(1), 47-69. 208.

Geib, M., Reichold, A., Kolbe, L., and Brenner, W., (2005). "Architecture for Customer Relationship Management Approaches in Financial Services," in the 38th Annual Hawaii International Conference on System Sciences (HICSS '05), pp. 240b-240b.

Gholami, S. and Sabbir Rahman, M., (2012), "CRM: A Conceptual Framework of Enablers and Perspectives", Business and Management Research, Vol. 1, No. 1; March 2012. Retrieved from www.sciedu.ca/bmr

Grant, R. M., (1998), “Contemporary strategy analysis”, (3rd ed.), Malden, Blackwell.

Gray, P. and Byun, J., (2001) "Customer Relationship Management". Centre for Research on Information Technology and Organisations, University of California, Version 3-6.

Hansotia, B., (2002), "Gearing up for CRM: Antecedents to successful implementation", Journal of Database Marketing, 10(2), 121-132.

http://www.softwareadvice.com/crm/?layout=var_ch1, retrieved on 12th May, 2015

Hung Nguyen, Norma Harrison, (2018) "Leveraging customer knowledge to enhance process innovation: Moderating effects from market dynamics", Business Process Management Journal, https://doi.org/10.1108/BPMJ-03-2017-0076

Iriana, R. and Buttle, F., (2006), "Strategic, Operational, and Analytical Customer Relationship Management: Attributes and Measures," Journal of Relationship Marketing, vol. 5, pp. 23-42.

Jayachandran, S., Sharma, S., Kaufman, P., \& Raman, P., (2005), "The role of relational information processes and technology use in customer relationship management", Journal of Marketing, 69(4), 177-192. 
Juran, J.M., (1964), “Managerial breakthrough”, New York: McGraw-Hill.

Kale, S. H., (2004), "CRM Failure and the Seven Deadly Sins". Marketing Management, $13(5), 42-46$.

Limayem, M. (2006), "Customer relationship management: Aims and objectives". Tehran: Tarbiat Modares University of Tehran.

Liza Nora, (2019) "Trust, commitment, and customer knowledge: Clarifying relational commitments and linking them to repurchasing intentions", Management Decision, https://doi.org/10.1108/MD-10-2017-0923

Lun, Z., Jinlin, L., \& Yingying, W., (2008), "Customer relationship management system framework design of Beijing Rural Commercial Bank". In Proceedings of the IEEE International Conference on Service Operations and Logistics, and Informatics (IEEE/SOLI 2008), 12-15 Oct. 2008, (pp. 97-101).

Mayron, D., (2015), "The 4 Core Components of CRM", Customer relationship Management, April, (2015).www.destinationCRM.com. Retrieved on Feb., 2018.

Mendoza, L.E., Marius, A., Pérez, M., \& Griman, A.C., (2007), "Critical success factors for a customer relationship management strategy", Information and Software Technology, 49, 913-945.

Mohammad H. Eslami, Nicolette Lakemond, (2016) "Knowledge integration with customers in collaborative product development projects", Journal of Business \& Industrial Marketing, Vol. 31 Issue: 7, pp.889-900, https://doi.org/10.1108/JBIM05-2014-0099

Moutot, J.M. and Bascoul, G., (2008), "Effects of Sales Force Automation Use on Sales Force Activities and Customer Relationship Management Processes", Journal of Personal Selling \& Sales Management 2, 8(2), 167-18 4.

Nejatian, H., Sentosa, I., Piaralal, S. K. and Bohari, A. M., (2011), "The influence of customer knowledge on CRM performance of Malaysian ICT companies: a structural equation modeling approach" International Journal of Business and Management, Vol. 6, pp. 181.

Nuri, H., (2014), "Review and application of theoretical models of customer relationship management on organizational productivity", (3), 222-227.

Öztaysi, B., Kaya, T. and Kahraman, C., (2011), "Performance comparison based on customer relationship management using analytic network process", Expert Systems with Applications, 38, 9788-9798.

Pass, L. \& Kuijlen, T., (2001), "Towards a general definition of customer relationship management". Journal of Database Marketing, 9(1), 51-60.

Parvatiyar, Atul and Jagdish N. Sheth (2001), "Conceptual Framework of Customer Relationship Management," in Customer Relationship Management-Emerging Concepts, Tools and Applications, Jagdish N. Sheth, Atul Parvatiyar, and G. Shainesh, eds. New Delhi, India: Tata/McGraw-Hill, 3-25.

Paulissen, K., Milis, K., \& Brengmann, M., (2005). "Customer relationship management systems research: Voids in the current literature". AMCIS 2005 Proceedings, Omaha (pp. 194-204).

Payne, A., and Frow, P., (2004). "The role of multichannel integration in customer relationship management". Industrial Marketing Management, 33: 527-538.

Payne, A., and Frow, P., (2005). "A Strategic Framework for Customer Relationship Management". Journal of Marketing, 69: 167-176.

Pedron, C. D., and Saccol, A. Z., (2009), "What Lies behind the Concept of Customer Relationship Management? Discussing the Essence of CRM through a Phenomenological Approach", Brazlian Administration Review (BAR), 6(1), 34-49. 
Pakistan Journal of Humanities and Social Sciences, 7(1), 2019

Plessis, M. D. and Boon, J. A., (2004), "Knowledge management in e Business and customer relationship management: South African case study findings", International Journal of Knowledge Management, 24(1), 73-86.

Rababah, K., Mohd, H. and Ibrahim, H., (2011), "Customer Relationship Management (CRM) process from theory to practice: the pre-implementation plan of CRM system", International Journal of e-Education, e-Business, e-Management and eLearning, Vol. 1 No. 1.

Ragins, E. J. and Greco, A. J., (2003), "Customer relationship management and e-business: More than a software solution", Review of Business, 24, 25-30.

Rahimi, R., (2014), "Organisational culture perspective and implementing customer relationship management (CRM) in hotel industry: case of a chain hotel in the UK", Doctoral Dissertation Summary, European Journal of Tourism Research, Vol. 8, pp. $162-165$.

Rahimi, R., (2017), "Customer relationship management (people, process and technology) and organizational culture in hotels: Which traits matter?", International Journal of Contemporary Hospitality Management, Vol. 29 Issue: 5, pp.1380-1402, doi: 10.1108/IJCHM-10-2015-0617.

Rahimi, R. and Gunlu, E., (2016), "Implementing customer relationship management (CRM) in hotel industry from organisational culture perspective", International Journal of Contemporary Hospitality Management, Vol. 28 No. 1, pp. 89-112.

Rahimi, R., Nadda, V. and Wang, H., (2015), "CRM in tourism", in Nilanjan, R. (Ed.), Emerging Innovative Marketing Strategies in the Tourism Industry, 1st ed., IGI Global, Pennsylvania, pp. 16-43.

Raisinghani, M., (2005), "CRM systems in German hospitals: illustrations of issues \& trends", Journal of Cases on Information Technology, vol. 7, pp. 1-26.

Rapp, A., Trainor, K. J., \& Agnihotri, R., (2010), "Performance implications of customer linking capabilities: Examining the complementary role of customer orientation and CRM technology", Journal of Business Research, 63(11), 1229-1236.

Reicher, R., \& Szeghegyi, A., (2015), "Factors Affecting the Selection and Implementation of a Customer Relationship Management (CRM) Process", Acta Polytechnica Hungarica, Vol. 12, No.4, 183-200.

Sanayei, A., and Sadidi, M., (2011), "Investigation of Customer Knowledge Management (CKM) Dimensions: A Survey Research", International Journal of Business and Management, 6(11), p234.

Sanaz Kargaran, Mona Jami Pour, Hossein Moeini, (2017) "Successful customer knowledge management implementation through social media capabilities", VINE Journal of Information and Knowledge Management Systems, Vol. 47 Issue: 3, pp.353-371, https://doi.org/10.1108/VJIKMS-11-2016-0066

Shang, S, and Fen, Y., (2006). "Understanding the Technology and Organizational Elements of Customer Relationship Management Systems". Proceedings of the twelfth Americas Conference on Information Systems, Acapulco, Mexico 2006

Shang, S., C., and Lin, j., S., (2005). "A Model for Understanding the Market-orientation Effects of CRM on the Organizational Processes". Proceedings of the Eleventh Americas Conference on Information Systems, Omaha, NE, USA 2005.

Shu-Mei Tseng, (2016) "The effect of knowledge management capability and customer knowledge gaps on corporate performance", Journal of Enterprise Information Management, Vol. 29 Issue: 1, pp.51-71, https://doi.org/10.1108/JEIM-03-2015-0021

Sin L.Y.M., Tse A.C.B. \& Yim F.H.K., (2005). "CRM: conceptualization and scale development”. European Journal of Marketing, 39(11/12), 1264-1290. 
Speier, C. and Venkatash, V., (2002), "The hidden minefields in the adoption of sales force automation technologies". Journal of Marketing, Vol. 66 (3), July, pp. 98 - 111.

Tamošiūniene, R., and Jasilioniene, R., (2007), "Customer relationship management as business strategy appliance: Theoretical and practical dimensions", Journal of Business Economics and Management, 8(1), 69-78. http://doi.org/10.1080/16111699.2007.9636154.

Thompson, S.H., Paul Devadoss, B., and Shan, L., (2006), "Towards a Holistic Perspective of Customer Relationship Management (CRM) Implementation: a Case Study of the Housing and Development Board", Singapore. Decision Support Systems, 42, 16131627.

Wu He, Weidong Zhang, Xin Tian, Ran Tao, Vasudeva Akula, (2019) "Identifying customer knowledge on social media through data analytics", Journal of Enterprise Information Management, Vol. 32 Issue: 1, pp.152-169, https://doi.org/10.1108/JEIM-02-20180031

$\underline{\mathrm{Xu}}, \mathrm{M}$., and Walton, J., (2005),"Gaining customer knowledge through analytical CRM", Industrial Management \& Data Systems, Vol. 105 Issue: 7, pp.955971, https://doi.org/10.1108/02635570510616139.

Yim F., Anderson R., \& Swaminathan S., (2004). "Customer relationship management: its dimensions and effect on customer outcomes". Journal of Personal Selling \& Sales Management, 24(4), 265-280.

Zablah, A.R., Bellenger, D.N. and Johnston, W.J., (2004), "An evaluation of divergent perspectives on customer relationship management: towards a common understanding of an emerging phenomenon”, Industrial Marketing Management, Vol. 33 No. 6, pp. 475-489.

Zeng, Y. E., Wen H. J., \& Yen, D. C., (2003),"Customer relationship management (CRM) in business-to-business (B2B) e-commerce", Information Management \& Computer Security, Vol. 11 Iss 1 pp. $39-44$.

Zhang, G., Chen, Y. and Fu, C., (2006), "A study on the relation between enterprise competitive advantage and CRM based on data mining," in International Technology and Innovation Conference (ITIC 2006), pp. 1710-1714. 
Pakistan Journal of Humanities and Social Sciences, 7(1), 2019

Appendix - A

CRM Software systems Categories

\begin{tabular}{|c|c|c|}
\hline $\mathbf{S r}$ & Category & Software Name \\
\hline 1 & \multicolumn{2}{|l|}{ Call Center and Contact Management } \\
\hline 1 & work inside Outlook & Prophet CRM \\
\hline 2 & integrated with email accounts & Prosper Works CRM \\
\hline 3 & Marketing campaigns and pricing structure & Salesfusion \\
\hline 4 & Call Center & 3CLogic Cloud Contact Center \\
\hline 5 & Automate client data entries by googlePlaces & CallProof \\
\hline 6 & Call Center & CorvisaOne \\
\hline 7 & hosted call center & Five9 Virtual Call Center \\
\hline 8 & help desk \& call center & FrontRange Solutions HEAT \\
\hline 9 & Call Center & inContact Hosted Call Center \\
\hline 10 & telephony Features & Nextiva VoIP \\
\hline 11 & Mobile CRM for Android, Apple and Blackberry & SalesNOW \\
\hline 12 & contacts, email campaign & SalesOutlook CRM \\
\hline 13 & Call Center & ServicePattern \\
\hline 14 & inbound \& outbound campaigns & Spark by Marketo \\
\hline 15 & Call Center & Talkdesk Call Center \\
\hline 16 & Call Center & Virtual Contact Center by $8 x 8$ \\
\hline 17 & Call Center & Vocalcom Cloud Contact Center \\
\hline 18 & Call Center & Zipwire \\
\hline 19 & Call Center Tool & Aspect Workforce Optimization \\
\hline 20 & Call Center & Centurion, Inc. CARES \\
\hline 21 & Call Center & Contivio Contact Center \\
\hline 22 & Call Center & DYL Lead Manager \\
\hline 23 & Customer Contact History & ePowerCenter \\
\hline 24 & Inbound \& Outbound & LeadLander \\
\hline 25 & Live Chat & LiveAgent \\
\hline 26 & Marketing/Sales, Call Center & OASIS \\
\hline 27 & Call Center & Oracle Contact Center Anywhere \\
\hline 28 & CM \& Sales automation & Reflect CRM \\
\hline 29 & CM \& Sales automation & Relenta CRM \\
\hline 30 & Presentation and proposals & SAVO \\
\hline 31 & Call Center & SMART QUEUE \\
\hline 32 & most sizes and phone interactions & Snapforce CRM \\
\hline 33 & Call Center & Solgari \\
\hline 34 & CCM / Call Center & Synchrony \\
\hline 35 & CCM / Call Center for small \& Midsize & Synchrony Express \\
\hline 36 & Call Center & Telemation \\
\hline 37 & custom CRM to build & TrackVia \\
\hline 38 & Call Center & USAN \\
\hline 39 & customer life cycle / Outlook, Gmail & Vtiger CRM On Demand \\
\hline 40 & CM, Sales , Mkt automation & Zurmo \\
\hline 41 & Email \& Calendar & ContactWise CRM \\
\hline 42 & contacts and email campaigns & Hatchbuck \\
\hline 43 & Sales contacts for small and medium business & Infusionsoft \\
\hline 44 & Email Marketing CRM & Silverpop \\
\hline 45 & Client Info \& Communication & Gazelle \\
\hline 2 & Social Media CRM & \\
\hline 1 & Social Media Integration & act-on \\
\hline 2 & Social Media Integration for enterprise & Falcon Social \\
\hline 3 & Social CRM Small and Midsize Business & Batchbook \\
\hline 4 & Social CRM & Gigya \\
\hline 5 & Social Media & Jive \\
\hline 6 & Social Media & MangoApps \\
\hline 7 & Sales Force Automation and Social Media & Nimble \\
\hline 8 & Social CRM & QuestBack Enterprise Feedback Suite \\
\hline 9 & Social CRM, Channel Management & RelateIQ \\
\hline 10 & Social Collaboration and advanced Analytics & SAP Cloud for Service \\
\hline
\end{tabular}




\begin{tabular}{|c|c|c|}
\hline 11 & Market analytics and social collaboration & SAP Marketing Suite \\
\hline 12 & Social CRM \& Campaigns & Social-ID Marketing Platform \\
\hline 13 & Social CRM & uberVU \\
\hline 14 & Multimedia & APLICOR 3C \\
\hline 15 & Social Marketing suite & Salesforce Marketing Cloud \\
\hline 16 & Customer Support and social CRM & ScribbleLive \\
\hline 17 & Marketing, social Media, Analytics, CSS & Answerbase \\
\hline 3 & Leads Management & \\
\hline 1 & Leads & ActiveDEMAND \\
\hline 2 & Sales leads for Mac & Element CRM \\
\hline 3 & Contacts and Interactions & Infor CRM (formerly Saleslogix) \\
\hline 4 & identify opportunities & Infor Epiphany \\
\hline 5 & Leads Management & LeadMaster \\
\hline 6 & Forecast future sales & NetSuite \\
\hline 7 & B2B contact management & PipelineDeals \\
\hline 8 & Leads to email campaigns & SharpSpring \\
\hline 9 & Lead, Opportunity and sales Management & TrackerRMS CRM \\
\hline 10 & Marketing campaigns & ActiveCampaign \\
\hline 11 & Marketing & Adobe Marketing Cloud \\
\hline 12 & Email Marketing CRM & CampaignerCRM \\
\hline 13 & Customer Analytics Tracking & Click2Coach Cloud \\
\hline 14 & Email Marketing CRM for small Business & Constant Contact \\
\hline 15 & Track Leads & Contactability LeadManager \\
\hline 16 & from leads to deal close & Oracle Marketing Cloud \\
\hline 17 & Interactive Website for Appointment System & CorkCRM \\
\hline 18 & Track Leads & CRMnext \\
\hline 19 & Chat Solution for Small \& Midsize & CustomerICare \\
\hline 20 & lead managements & Genoo \\
\hline 21 & lead managements & HubSpot \\
\hline 22 & Leads Management \& Marketing teams & InsideView \\
\hline 23 & Small business contacts \& Leads & Insightly \\
\hline 24 & Manage content and Campaigns & Kapost \\
\hline 25 & Marketing automation & Launchpad \\
\hline 26 & Leads Management & LeadLife \\
\hline 27 & Email Marketing & Mailigen \\
\hline 28 & Market Automation & Net-Results Marketing Automation \\
\hline 29 & Sales Team \& Email Marketing & ONTRAPORT \\
\hline 30 & Marketing & Oracle Responsys \\
\hline 31 & SMB Leads management & Pipedrive \\
\hline 32 & leads, sales force, marketing & Pivotal CRM \\
\hline 33 & DMS , Automotive, leads management & Q-GPS \\
\hline 34 & Marketing & REthink \\
\hline 35 & Leads and customer support & Saleslogix \\
\hline 36 & Marketing \& Analytics & SAS Customer Intelligence \\
\hline 37 & SMB \& Midsize & Sellsy \\
\hline 38 & Campaign Management \& Market analytics & Teradata Integrated Marketing Cloud \\
\hline 39 & workflow for leads & Velocify \\
\hline 40 & automate workflow, CM, & Zoho CRM \\
\hline 41 & B2B leads, email marketing tool & Salesforce - Pardot \\
\hline 4 & Project Management & \\
\hline 1 & Project Management & bpm'online Sales \\
\hline 2 & Customer Support \& project Management & EBSuite \\
\hline 3 & Project Mgmt., help desk, sales, mkt & WORKetc \\
\hline 4 & Sales, contacts, projects, Mac Based. & marketcircle \\
\hline 5 & Project Management and CRM for Contractors & JobNimbus \\
\hline 5 & Eneterprise CRM & \\
\hline 1 & B2B \& B2C Sales & Base CRM \\
\hline 2 & B2B Sales Automation & CallidusCloud Marketing Automation \\
\hline 3 & CRM Customizable for midsized business & Ivinex CRM \\
\hline 4 & B2C marketing and Service & KANA Express \\
\hline 5 & B2B marketer & Marketo \\
\hline
\end{tabular}


CRM for Mid and Enterprise/Industry specific solutions as your business grows

varieties of Business Industries

open source, customizable as needs

Sales and Marketing, Telemarketing

Sales \& Marketing automation

CRM for Small Business

small business and midsized

small business

Small and Mid-size

Open Source, All Business Sizes

Automated Marketing

Small \& Large Enterprises

small to Midsize Businesses

small Business contact management

small \& Midsize Business

customizable cloud base

Automation for Small Business

B2B Market and Sales

SBM, sales automation, Marketig, CS

Sales and Marketing

Sales force Automation

Sales Process

Sales Process

compatible on Mac and Windows

Sales Workflow

Sales, Marketing and customer service

Sales Process and email Marketing

Sales features for Small \& Midsize

Sales Process

Marketing \& Sales

Sales Management

Sales, Service and Marketing

Sales, Marketing and customer service

Mid and Enterprise

SFA, customer support , email marketing

Smart Selling Tool

Sales and Marketing

workflow, Sales \& Marketing

mobile apps integrated with SAP's

workflow, Sales \& Marketing

Sales \& Marketing, outlook, Gmail

Process Automation

Specialized CRM

Mortgage Brokers

Mortgage Brokers

Mortgage CRM

Microsoft Dynamics CRM

Sage CRM

Salesforce.com

SugarCRM

VanillaSoft Pro

Workbooks

Act!

AmoCRM

Capsule

Commence CRM

Deskera CRM

Fision

GoldMine

Horizon HQ

Less Annoying CRM

Live Chat

LogicBox CRM

OnePageCRM

Radius

Really Simple Systems

SafeSoft Cloud Contact Center

BlueCamroo

Mothernode CRM

Pipeliner CRM

SalesExec

Apptivo

BigContacts

Nutshell

Omniprise CRM

OnContact CRM 7

Oracle CX for Sales

Oracle E-Business Suite CRM

Oracle Siebel CRM

PeopleSoft CRM

PlanPlus Online

Qvidian Sales Playbooks

SafeSoft Cloud Contact Center

SAP - CRM

SAP Cloud for Sales

SimplyCast

SprinxCRM

Zoho Support

\section{ARCHITECTURE}

\begin{tabular}{l|l|l}
\hline 1 & architecture, engineering and construction (AEC) & Cosential
\end{tabular}

BNTouch Mortgage CRM

Pulse Mortgage CRM

Vantage Integrated Production (VIP)

\begin{tabular}{l|l|l}
2 & Architecture, engineers. Salesforce & Deltek Vision
\end{tabular}

\begin{tabular}{l|l} 
construction & FollowUP Power
\end{tabular}

Contractor's

Real estate Industry

Real estate specific CRM

Real estate Agencies

homebuilder and real estate agents

Real Estate

Real Estate CRM

\begin{tabular}{l|l}
11 & Real Estate CRM
\end{tabular}

\begin{tabular}{l|l}
\hline 7.2 & FINANCIAL
\end{tabular}

Contractor's Cloud

Lasso CRM

Propertybase

REfindly CRM

SmartTouch Interactive

xRE by Ascendix

Realtiva

Referral Maker CRM 


\begin{tabular}{|c|c|c|}
\hline 1 & Account Management System for Insurance agent & TechCanary \\
\hline 2 & financial service industry & SoftVu \\
\hline 7.3 & NONPROFIT & \\
\hline 1 & nonprofits & Salsa cosm \\
\hline 2 & Non-Profit Organization & Qgiv \\
\hline 3 & Non-Profit Organization / raising funds & The Raiser's Edge \\
\hline 7.4 & HEALTHCARE & \\
\hline 1 & HealthCare & Healthcare Relationship Cloud \\
\hline 2 & HealthCare & Physician Relationship Management System \\
\hline 3 & Life and Health Insurance agencies & AgencyBloc \\
\hline 4 & Insurance agencies and agents & AgentCubed \\
\hline 5 & Advertising ,Healthcare, Technology & eTrigue Demand Center Software \\
\hline 6 & Insurance Industries & Vertafore Pipeline Manager \\
\hline 7.5 & JEWELERY & \\
\hline 1 & jewelers CRM & Diamond Relations \\
\hline 7.6 & SCHOOL/GOVERNMENT & \\
\hline 1 & Schools/ Governments CRM & WebQA \\
\hline 7.7 & TRAINING & \\
\hline 1 & Training Practice & Bloomfire \\
\hline 7.8 & ERP/CRM & \\
\hline 1 & ERP & BusinessMan CRM/ERP \\
\hline 2 & Predictive Analytics & Lattice Engines \\
\hline 3 & Predictive Analytics & Pega CRM \\
\hline 8 & Service Management & \\
\hline 1 & Service Based Companies & Bullhorn \\
\hline 2 & small business, service, medical & Creedenz \\
\hline 3 & Service Based Companies & Alert Stratus \\
\hline 4 & communication service provider(CSPs) & Amdocs Customer Management \\
\hline 5 & Mobile Application for Services business & BigWave \\
\hline 6 & Field Service Management & BlueFolder \\
\hline 7 & Service Desk Manager & CA Service Desk Manager \\
\hline 8 & IT Service Management & Cherwell Service Management \\
\hline 9 & Service Field Management & e-Service Suite \\
\hline 10 & Service Management & FieldAware \\
\hline 11 & Modular Customer Management & bxp software \\
\hline 12 & Service Management & FieldPower \\
\hline 13 & Field Service & My eToolbox \\
\hline 14 & Service Management & Onyx CRM \\
\hline 15 & Service Management & ProBusinessTools \\
\hline 16 & Customer service management & SpiceCSM \\
\hline 17 & IT help Desk with Multiple third Party service & SunView \\
\hline 18 & Customer Support & Freshdesk \\
\hline 19 & IT Service Management & FreshService \\
\hline 20 & Customer service and support & IntelliResponse Virtual Agent \\
\hline 21 & field service & Mhelpdesk \\
\hline 22 & Price conscious companies - Mac users & OnContact CRM \\
\hline 23 & Customer Support & PhaseWare Tracker \\
\hline 24 & Sales and support (SaaS) Software-as-a-service & Salesforce.com Service Cloud \\
\hline 25 & sales, Marketing, customer support & Socious Online Community \\
\hline 26 & Customer Support & TeamSupport \\
\hline 27 & Customer service & Aspect Unified IP \\
\hline 28 & Service Management & CSDP Service Relationship Management (SRM@) \\
\hline 29 & Help Desk & Cynergy Software \\
\hline 30 & Help Desk & Desk.com \\
\hline 31 & Customer service \& Marketing Teams & GoldMine Premium Edition \\
\hline 32 & Help Desk \& Incident Management & GoToAssist \\
\hline 33 & Client Support Process & HappyFox \\
\hline 34 & Help Desk & Help Desk Premier \\
\hline 35 & Help Desk & Help Scout \\
\hline 36 & Help Desk & HESK \\
\hline 37 & Help Desk Service & HP Service Manager \\
\hline
\end{tabular}


Pakistan Journal of Humanities and Social Sciences, 7(1), 2019

\begin{tabular}{|l|l|l|}
38 & Field Service Management & IFS Field Service Management \\
\hline 39 & Help Desk \& Management software & I'm OnCall \\
\hline 40 & Help Desk \& customer support & Kayako \\
\hline 41 & Process Management & LANDESK Service Desk \\
\hline 42 & Help Desk Suite & LiveHelpNow \\
\hline 43 & Service Desk & ManageEngine ServiceDesk Plus \\
\hline 44 & service \& support & Oracle Service Cloud \\
\hline 45 & Customer Services & OrangeCRM \\
\hline 46 & Customer Loyalty and Sales & RightNow CX \\
\hline 47 & Mobile Service Management & ServiceMinder \\
\hline 48 & Service Desk \& IT assets & ServiceNow Express \\
\hline 49 & Help Desk \& Customer service & ServicePRO \\
\hline 50 & Customer support & ServiceWise \\
\hline 51 & customer messaging system & StormPost \\
\hline 52 & Service desk management & Track-It! \\
\hline 53 & Customer support \& Marketing teams & UserVoice \\
\hline 54 & Management tools & 1 CRM \\
\hline 55 & help desk CRM & Samanage \\
\hline 56 & help Desk & Spiceworks \\
\hline 57 & Help Desk & Zendesk \\
\hline 58 & Plug in & Agiloft \\
\hline $\mathbf{9}$ & Knowledge Management & \\
\hline 1 & knowledge base & Inbenta \\
\hline 2 & Knowledge Management & SmartSupport \\
\hline 3 & knowledge Management, call center, help desk & Universal Knowledge \\
\hline 4 & IT Service Management, Health Care, Manufacturing & assyst \\
\hline 5 & SMB, Knowledge Management & Parature \\
\hline
\end{tabular}

